the absence of an external field depends upon the crystalline state of the source; for a polycrystalline indium source, it shows a maximum value of 20 per cent at the melting point. Experiments with single (non-cubic) crystals showed a dependence of the observed anisotropy upon the orientation of the counters with respect to the crystal axes.

Other topics involving atomic processes were the elastic scattering of gamma-rays, in which scattering by bound electrons is coherent with nuclear scattering and the orientation of radioactive nuclei by magnetic fields at low temperatures, which has been achieved with elements that form Tutton salts.

In sessions devoted to experimental techniques, reports were given by D. Walker and J. H. Fremlin (Birmingham) of the processes by which multiplycharged ions (for example, ${ }^{14} \mathrm{~N}^{6+}$ ) can be accelerated in a cyclotron and of the types of nuclear reaction that such relatively heavy nuclei produce. Particular interest was shown in an impromptu description given by R. Birge (Berkeley) of the bubble-chamber experiments initiated by Glaser at Michigan, in which ionizing particles cause ebullition in a superheated liquid.

\section{SECOND INTERNATIONAL CONGRESS ON RHEOLOGY}

$\mathrm{T}$

HE Second International Congress on Rheology was held in Oxford during July 26-31 and was attended by some 245 rheologists accompanied by about fifty visitors. The proceedings commenced with an address on "Rheology for Mathematicians", given by the president of the Congress, Sir Geoffrey Taylor, who discussed various way in which mathematicians can help rheologists and the attitude of practical rheologists to the pure mathematician.

The technical programme of the Congress consisted of six invited lectures as well as a number of sectional meetings run in parallel. Nearly half of the fortynine contributed papers dealt with properties of high polymers, and these provided the subject-matter for Section $A$ for the whole of the Congress. A short (half-day) Section $C$ was concerned with problems of lubrication, all other contributions being grouped into a miscellaneous Section $B$.

In drawing up the programme, the aim of the organizing committee had been to cover the extended field of "the study of the deformation and flow of matter" as widely as possible. The subjects of the invited lectures illustrate this policy: sur l'effet éléctrovisqueux (Mme. A. Dobry-Duclaux, Paris); rheological problems in the fabrication of plastics (Dr. R. S. Spencer, Midland, Mich.); rheology and applied mechanics (Dr. R. N. J. Saal, Amsterdam); rheological behaviour and the molecular jumping mechanism (Prof. F. H. Müller, Marburg); water association and hydrogels (Mr. E. Forslind, Stockholm); and biological problems for the rheologist (Dr. P. Eggleton, Edinburgh). As well as many papers on plastics and high polymers generally, sectional papers covered a wide range of materials-..for example, clays, metals, gelatine gels, flour doughs, diamonds, greases, bitumens and protoplasm. Discussions ranged from methods of viscometry to the study of chronic bronchitis in man and the diagnosis of pregnancy in the cow. Papers were read, and discussions took place, in English, French and German.

Most of the papers were circulated as preprints before the meeting opened; all of them, together with summaries of the discussions which followed, will be published in book form by Butterworth's Publications, Ltd., London, and will appear, it is hoped, within about six months. In conjunction with the Congress there was a small exhibition of commercially available rheological apparatus, and an Oxford bookseller also arranged a special display of rheological books.

There were three evening meetings. At the first of these, a number of technical films was shown, including one illustrating Sir Geoffrey Taylor's own investigations on the dragging of anchors. Another evening was devoted to a discussion on international organization of rheology, at which the Intermational Union of Pure and Applied Physics was represented by its president, Prof. N. F. Mott (Bristol), the International Union of Chemistry by Mme. A. Dobry-Duclaux (Paris) and that of Theoretical and Applied Mechanics by Prof. J. M. Burgers (Delft). It was decided to form an International Committee on Rheology consisting initially of one representative each from all national groups devoted solely to the study of rheology, with power to co-opt individual rheologists from countries where no such groups as yet exist. The membership of the committee is temporary, until the national societies can elect their own representatives. Later in the Congress, the representatives of France (Prof. H. Weiss), Germany (Prof. F. H. Müller), Great Britain (Mr. A. G. Ward), Netherlands (Dr. R. N. J. Saal) and United States (Dr. R. S. Spencer) met under the chairmanship of Mr. Ward, and co-opted Prof. B. Gross (Brazil), Prof. M. Reiner (Israel) and Prof. A. Peterlin (Yugoslavia). It was resolved also to send invitations to rheologists in India, Japan and the Scandinavian countries. The purposes of the Committee were laid down as follows : "(1) To be a permanent body for organizing future International Congresses on Rheology, (2) to encourage new national organizations for the study of rheology, and (3) to act as co-ordinating body in other international co-operations in the field of rheology". Dr. R. N. J. Saal (Amsterdam) is acting as temporary secretary.

A third evening was devoted to a discussion on nomenclature and symbols. A number of reports formed a basis for the discussion, including that by Prof. J. M. Burgers and Dr. G. W. Scott Blair, published in 1949 under the auspices of the now defunct Joint Committee on Rheology. Dr. H. Leaderman (Washington, D.C.) reported on the still tentative but valuable "proposals for nomenclature for linear visco-elastic behavior" put forward by the Committee on Nomenclature of the (American) Society of Rheology. Following the discussion, certain recommendations were sent to Dr. Saal as secretary of the new International Committee.

At the Congress dinner, held in the Hall of Christ Church, Sir Ben Lockspeiser, as guest of honour, in reply to the toast of "The Guests", proposed by the president, summarized the history of the British Society of Rheology and recalled the First Congress held in Scheveningen in 1948. Dr. R. S. Spencer, president of the American Society, proposed "International Rheology", to which Mme. Dobry-Duclaux replied in French.

The Congress was closed by Prof. A. Peterlin (Yugoslavia), who expressed the gratitude of overseas rheologists to their British colleagues who had organized the Congress. Under the auspices of the newly formed International Committee, it is hoped that other equally pleasant and profitable congresses will be held in future years. G. W. ScotT BLarr 